\title{
CECIL: UNA AUTOBIOGRAFÍA NOVELESCA DE MANUEL MUJICA LÁINEZ
}

Cecil: A fantastic autobiography of Manuel Mujica Láinez

David Choin*

\section{RESUMEN}

En Cecil, Manuel Mujica Láinez parte de la tradición literaria del perro-narrador para entregar al lector confesiones íntimas sobre su vida y su obra desde que dejó Buenos Aires para instalarse en su residencia de El Paraíso, en la sierra cordobesa. Esta autobiografía del escritor argentino narrada por su perro Cecil, desvela la intimidad de un hombre dispuesto a contar lo que nunca mencionó en ningún reportaje o entrevista.

Palabras clave: Literatura argentina, autobiografía, ficción, Mujica Láinez, perro-narrador.

\begin{abstract}
In his novel Cecil, Manuel Mujica Láinez, part of the literary tradition of the dog-narrator to deliver the reader intimate confessions about his life and work since he left Buenos Aires to be installed in the Cordoba mountain. This autobiography of the Argentinian writer narrated by his dog Cecil, reveals the intimacy of a man ready to tell them what he never mentioned in any report or interview.
\end{abstract}

Key Words: Argentine literature, autobiography, fiction, Mujica Láinez, dog-narrator.

Universidad Técnica Particular de Loja, Facultad de Lengua y Literatura. Ecuador.

Correo electrónico: choindavid@hotmail.com

Recepción: 20/11/13. Aceptación: 23/03/14. 
"No hay creación sin tradición ni tradición sin creación" Carlos Fuentes

Es frecuente que la figura del autor oculte a la del escritor pero en el caso de Manuel Mujica Láinez esta desdeñosa asimilación, a la par que los achaques constantes de sufridores, contribuyó a crear una "leyenda negra" mujicense alimentada por anécdotas que fraguaron una versión frívola de su persona; ávido comensal de almuerzos burgueses y solicitado entrevistado en suplementos culturales y revistas. No era usual entonces que un escritor frecuentara el primer plano, lo que suscitó celos, envidia y rencores. A pesar de ello, el escritor porteño fue un sujeto imprescindible del ámbito artístico de los años 60 argentinos.

Pero, ¿por qué dedicar tiempo y malgastar tinta escribiendo sobre Mujica Láinez, cuando perfectamente se podría adentrar en la bibliografía que estudia a exitosos autores argentinos como son Tomás Eloy Martínez, Ricardo Piglia, Pablo De Santis, etc.? Las primeras palabras que me vienen a la mente se proyectan a rendir homenaje a una figura atípica, una persona que no se afanó por situarse en las líneas de vanguardia ni por pertenecer a los círculos de culto. Racional, sensible, cultivador del pasado y de la belleza, Manuel Mujica Láinez creó tantos mundos como le fue posible con el fin de deleitar a sus lectores, conmover el espíritu y estimular los sentidos por la memoria.

Como se evidencia, queda mucho por decir de este gran escritor y de su obra. Éste es el propósito de aquella columna para que, esperémoslo, se realice la definitiva inclusión de Manuel Mujica Láinez en el canon de los autores argentinos. De las treinta obras del escritor porteño, la mayoría ha sido apreciada a su justo valor asociándose su obra temprana al Realismo Mágico ${ }^{1}$, al Realismo decimonónico de Proust $^{2}$, a la novela histórica ${ }^{3}$ pero nunca se ha realizado un estudio detallado de la autobiografía novelada del escritor contada por su perro, Cecil ${ }^{4}$ (1972), a pesar de que el mismo autor haya declarado en una entrevista a María Esther Vásquez: "Quiero a ese libro porque es el único autobiográfico en su totalidad" (1966: 114).
Siempre releva de una azarosa elección destacar un título de una extensa obra, aún más cuando se es consciente de excluir a las más conocidas pero ésta pretende, en primer lugar, demostrar por qué Manucho ${ }^{5}$ decidió que su perro contara su vida sólo desde que llegó a su residencia cordobesa del Paraíso; dar a conocer, en segundo lugar, una novela por muchos ignorada; $y$, en tercer lugar, ennoblecer el trabajo del escritor revelando otras conexiones literarias enriquecedoras, en este caso preciso, con autores que utilizaron el recurso del perro narrador-protagonista cuyo punto de partida radica en Riquet de Anatole France.

\section{La tradición literaria del perro-narrador}

Las relaciones de los animales con los seres humanos han inspirado desde hace siglos una vasta literatura pero la tradición del perroprotagonista es una de las más tempranas ya que inició con El coloquio de los perros de Cervantes en el que los canes Cipión y Berganza adquieren por las noches el don del habla, dialogan y razonan con una sensibilidad, sentido común y comprensión extraordinariamente más humanos que los que suele mostrar el propio homo sapiens. Otros escritores de talla han seguido después con dicho experimento, desde Jack London (Colmillo blanco, 1906), Corazón de perro (1925) de Bulgákov pasando por Virginia Woolf (Flush, 1933) hasta Paul Auster (Tombuctú, 1999). En la narrativa hispanoamericana ya había un antecedente de perro hablador en Los perros hambrientos (1938), del peruano Ciro Alegría. Cabe añadir que existe en inglés un libro titulado Dog stories $^{6}$ que incluye relatos excelentes sobre perros-protagonistas de O. Henry ("Memoirs of a yellow dog", 1906), P.G Wodehouse ("The mixer" publicado en The Man with Two Left Feet, 1917), Mark Twain ("A Dog's Tale", 1903), Chejov ("Kashtanka", 1887), Chesterton ("The Oracle of the dog", 1926) y muchos más. Más recientemente, tuvo buena acogida Faycán, memorias de un perro vagabundo (2007) de Víctor Doreste. Asimismo se editó en el ámbito editorial hispanófono una compilación titulada Las mejores historias sobre perros ${ }^{7}$. 
De las referencias bibliográficas citadas en el párrafo anterior, merece destacarse Flush, la novela de Virginia Woolf en la que un cocker spaniel cuenta la vida de la poetisa Elizabeth Barret-Browning, por el parecido narratológico y temático que guarda con Cecil de Mujica Láinez a la diferencia de que la obra de Woolf no es autobiográfica. Es decir que el escritor argentino se inserta en una tradición retomando el modelo de una autora que leyó y apreció. Quizás Flush: A Biography no sea un libro de tanto valor literario como pueden serlo Orlando o Entre actos pero indaga indudablemente un aspecto tan caro a Manuel Mujica Láinez como es la comunicación silenciosa entre un animal y un ser humano -que no se limita en el escritor argentino a esta única relación sino que se expande también a los objetos- desde un punto de vista eminentemente modernista. Al igual que Cecil, Flush es una obra que combina la ficción, el perro expresa con su voz los pensamientos que pueblan su conciencia, con la no ficción en tanto que narra la historia de su ama Elizabeth Barret Browning.

Si Mujica Láinez conoce la tradición de los perros en la literatura, lo mismo vale sin sorpresa para Cecil quien alza las orejas cuando Leonardo, un amigo especial de Mujica Láinez sobre el cual volveremos más adelante, "le preguntó a mi dueño si conocía el testamento de Blemie, el perro de Eugene O'Neill" (p.68). En efecto, en el libro La última voluntad y testamento de un perro distinguido, un perro llamado Blemie pide a sus dueños que enmarquen su collar y placa, y que los cuelguen en una pared orientada hacia el oeste, en donde todos los perros encuentran el paraíso ${ }^{8}$. Agradado por la amable referencia, Cecil sobresalta cuando escucha en boca de este mismo "amigo" que ésas eran “extravagancias poéticas de O'Neill, ya que un perro, felizmente, es incapaz de abrigar tales ideas", (p. 68). Enseguida, el can arremete contra el intruso:

$¡$ ¡A maula! ¡ah guacho! (Perdóneseme el vocabula $\neg$ rio, y téngase en cuenta que nací en una estancia.) ¿Cómo se atrevió? ¿cómo osó hablar de mis congéneres así? ¿qué sabe Leonardo de nosotros? ¿Para qué le habrá otorgado Dios esa facha mística, que mi amo compara con el autorretrato de Durero? De mí aseguro que creo tanto en la otra vida como en el Ser que a todos nos trajo al mundo. No creo, como los perros mahometanos amigos de Blemie, en un Cielo de perras-huríes. Para mí no existiría el Cielo si en él no estuviera, conmigo, el Escritor; de lo contrario, el Cielo no sería tal. P. 68.

Este ataque no es inocente ya que más allá de la defensa de su honor, Cecil y Mujica Láinez reiteran una vez más el pacto de lectura de esta autobiografía novelesca, esto es, las confesiones del amo por su perro gracias al amor que los une $\mathrm{y}$ hace de sus mentes una sola.

Así, la obra de Manuel Mujica Láinez se incluye en una tradición literaria arraigada pero, a la vez, se singulariza en un juego narrativo inaudito en el que conviven los pensamientos del amo con los del perro entre los cuales se intercalan, periódicamente, consideraciones éticas y estéticas del Escritor no sin un humor negro característico de Mujica Láinez. Puede que, en un principio, el juego literario despiste, ya que el escritor escribe lo que piensa Cecil, visualizando éste lo que el escritor concibe.

Cecil resulta ser una obra difícil de encasillar en un único género ya que se sitúa a mitad de camino entre los pactos autobiográficos y novelescos. En palabras de Raúl Quesada quien estudió el autobiografismo en la obra de Manuel Mujica Láinez, contar su vida responde a:

ese impulso vital que lleva a uno a enfrentarse
consigo mismo para analizar su vida e ir forjándose
una propia identidad, tras haberse observado y
estudiado meticulosamente, con mucha paciencia.
A partir de ahí se va elaborando esa personalidad
que, condicionada por el temperamento del
escritor y por el contexto sociocultural específico
en el que se halle, por fin se decidirá mostrar a los
demás, que sea de dominio público, con todas las
consecuencias que una acción tan atrevida puede
conllevar. (Quesada Portero, 2010: 22).

En opinión del mismo Raúl Quesada, Cecil sería una autobiografía ficticia en tanto que adopta parcialmente la forma autobiográfica puesto que prevalece lo ficcional sobre lo factual. Efectivamente, el nombre del autor no corresponde con los de narrador y personaje. A pesar de todo, el escritor argentino se ve a 
sí mismo desde fuera a través de los ojos de su amado perro que, por su condición animal, está exento de los defectos humanos como la hipocresía o los prejuicios. En este sentido, los epígrafes de la obra son reveladores. El primero de Baudelaire "Tu te plais à plonger au sein de ton image..." ", magnifica el placer de verse en el mar como en un espejo deforme; en nuestro caso, el tamiz de reflexión será la conciencia del fiel Cecil quien podrá "decir cosas que depositaba en la memoria", como Cipión y Berganza en El Coloquio de los Perros de Cervantes, segundo epígrafe.

En esta obra el escritor esboza sus proyectos literarios- y no literarios- en un momento de tregua ${ }^{10}$. Por tanto, Cecil es una autobiografía especial porque relata su vida desde su decisión de abandonar Buenos Aires para trasladarse a las sierras cordobesas, esto es, narra su pasado inmediato y su presente. Así, se presentan transgresiones temáticas que nos adentran en la intimidad nunca desvelada de Mujica Láinez y de su alter ego Manucho: "su dandismo, su desparpajo mediático, sus declaraciones deliberadamente frívolas y su circulación por el mundo de una farándula singular" en palabras de Piña (2009: 3). Asimismo, el novelista argentino intenta rescatarse a sí mismo por medio del arte, siendo Cecil una autobiografía encubierta, puesta en boca del whippet del narrador. Ahondar en esta línea significa abrir una nueva perspectiva en los estudios mujicenses, y, por otra parte, permitiría "observar la posible incorporación del sistema literario porteño a una corriente estética de la que generalmente ha sido apartado" (Niemetz, 2010: 391).

Presentar de manera coherente el baúl de recuerdos y vivencias del pasado reciente suponía un reto para el escritor. Así, en los ocho primeros capítulos Cecil se presenta a sí mismo y a "los moradores sobrenaturales y pasados de la quinta" (Cecil, p. 55). Del capítulo 9 al 11 presenta los ocupantes actuales: Manucho, su mujer, la madre del escritor, sus tías, Humberto, los criados y a los vecinos (Madame Pamela, Gunther). Seguidamente, dedica capítulos al abortado proyecto literario de Heliogábalo y al contexto histórico que lo rodeó; dos capítulos a Leonardo y cierra la obra con el relato de su excursión con amigos a las cuevas pintadas del Parque Arqueológico del Cerro Colorado (Córdoba). Con toda evidencia, esta estructura narrativa sustenta "su identidad como individuo y como artista" (Cecil, p. 31).

Este artículo no aspira a relatar anécdotas ampliamente reseñadas por los biógrafos de Mujica Láinez sino presentar, a través de esta obra, el pacto ficticio que une escritor y lectores; descubrir su carácter; dar a conocer sus motivaciones e impulsos literarios; destacar las claves interpretativas de su obra y, en última instancia, presentar sus consideraciones, reflexiones y diversos pensares sobre amigos, conciudadanos y temas universales.

\section{El pacto ficticio}

A primera vista, en Cecil, el juego de narradores se aparenta a unas voces intrincadas en una conversación apasionada. Sabemos quién participa de ella pero a veces, aun conociendo las voces de cada uno, cuesta distinguirlas. Sin embargo, y a pesar de que predomine la primera persona del singular, Mujica Láinez ha construido un sistema de referencias ineludibles que permite discernir cuando Cecil transmite los pensamientos de su amo, cuando expresa su propio sentir o cuando habla el propio autor. Concretamente, el perro es el narrador pero el protagonista es su amo: "Sí, me sitúo — reitero que tal vez por la magia del amor-en el cinematógrafo de su cabeza. Sé lo que sabe; soy testigo de lo que imagina; lo disfruto y lo sufro" (p. 9). Más adelante prosigue: "pero nadie lo conoce mejor, ya que comparto su concien $\neg$ cia, y no hago más que reproducir, como un servil disco de fonógrafo, lo que mis orejas recogen contiᄀnuamente", (p. 11). "Debería explicar ahora cómo veo y leo con sus ojos; cómo me refugio en la mente del Escritor y ob $\neg$ servo lo que piensa. Sería explicar lo inexplicable", (p. 9). De esta manera, se enuncian explícitamente las reglas de lo que se va a leer y por qué se lee. 
Por el grado de sinceridad postulado, todo lo dicho está entonces sujeto a unas confesiones involuntarias, espontáneas, desprovistas del tamiz racional de lo políticamente correcto y la autocensura que conlleva. En la autobiografía tradicional el yo analiza y narra. Mujica Láinez se libra de estas ataduras; él analiza, pero quien narra es su perro Cecil. Aun así, conviene señalar que existe otro matiz en la narración. En efecto, cuando Cecil transmite los pensamientos de su amo, no los reproduce tal cual pasaron por la mente de Mujica Láinez, a no ser que acuda al estilo directo y cite entre comillas como veremos más adelante, sino que los reformula interpretando lo que llegaría a sentir su amo, imaginando sus sentimientos y, por supuesto, exagerando sus reacciones. Directamente relacionado con el proceso de indagación autobiográfica, se halla el procedimiento del desdoblamiento: "gracias al cual la persona consigue distanciarse de una visión demasiado limitada y subjetiva de sí mismo, mediante la manipulación de los entes narrativos a los que habrá de recurrir a la hora de escribir: autor, narrador y protagonista". (Quesada Portero, 2010: 300).

Desde el inicio de su relato, Cecil deja claro que no es un animal cualquiera, sino que encarna la figura del narrador privilegiado: "el Escritor me necesitaba”, (p. 6). Por otra parte, la palabra "Escritor" aparece con mayúsculas por lo que se establece una evidente y reveladora distinción entre la figura del escritor y la del amo dado que cuando se refiera al segundo, el perro dirá simplemente "mi amo". En otros momentos, toma la voz el escritor y desaparece el perro narrador: ""Hay una etapa en mi vida de escritor, singular $\neg$ mente angustiosa: es la que se estira entre la termina $\neg$ ción de un libro y el comienzo del siguiente", (p. 19).

Otra clave del pacto de lectura de nuestra novela la representan las citas en estilo directo, identificables en el relato por sus convenciones estilísticas (dos puntos y comillas) como cuando Cecil señala "y dice: "Los he mandado poner ahí, para 'italianizar' la quinta, para que tenga más el aire de una 'villa', que de un cortijo o un cigarral español". Añade Cecil después: "Le he oído esa frase muchas veces", (p. 10).

Llegados a este punto conviene retomar dos conceptos que se completan para entender el alcance de la obra. El primero, el de "autor implícito" acuñado por E.M. Forster y W.C Booth que apuntan a una ficcionalización que el escritor hace de sí mismo mientras escribe. El segundo, el de "lector cómplice", según el cual el autor establece las reglas del juego literario, reservando un lugar privilegiado a los lectores que respetarán el pacto a fin de disfrutar de las confesiones plasmadas en la obra. Como hemos señalado anteriormente, Cecil deja claro en las primeras páginas del libro que sabe lo que su amo sabe porque el amor unió sus mentes. Quién no lo acepte se unirá al grupo de "Los de afuera, los otros, naturalmente que no cap $\neg$ tarán una interpretación tan extraña. A menos - cosa rara - que se trate de auténticos enamorados. Yo no puedo expresar sino lo que siento, y aquí está", (p. 9). En un intento de justificación Cecil se atreve a la única explicación que puede dar: la pasional.

Como vemos, la novela dista mucho de ser la simple narración de un animal como lo fueron los primeros eslabones de la tradición citados anteriormente. No; Cecil es juez y parte; es un animal especial, enamorado apasionado de su amo, capaz de adentrarse en los últimos recovecos de su alma para entregarnos, sin tapujos, a un Manuel Mujica Láinez sincero, liberado de las ataduras de la entrevista. Empero, conviene tener presente que él sigue siendo el autor.

\section{El perro y su amo}

Muchos críticos y periodistas se han esmerado en definir el carácter de Manuel Mujica Láinez pero, salvo contadas excepciones, pocos son los que han tenido el tino de hacer la distinción antes recalcada entre el escritor y su alter-ego público, y el hombre Manuel Mujica Láinez. En otras palabras, no interesa aquí reseñar la personalidad del escritor, harto conocida -aunque deformada a veces según la simpatía que haya despertado el escritor en el 
poco tiempo dedicado a la entrevista y otras en función de los chismes de la mundanidad bonaerense- sino desvelar la esencia de un ser entrañable, sincero y generoso.

Retomando los postulados enunciados en el apartado anterior, no se puede establecer distinción entre el carácter del amo y de su perro. Cecil ama tanto a su dueño que éste, involuntariamente, ha moldeado su carácter a imagen y semejanza del suyo. De modo que, hable el perro o el propio autor, lo que tenemos que leer es la confesión de un hombre experimentado y desengañado.

$\mathrm{Su}$ amor recíproco nacido de los paseos cotidianos, la soledad del trabajo de escritorio vespertino y las veladas en el fumoir sentados ambos en su sillón, han estimulado una afinidad infrangible entre ellos que les basta a sí mismos. En boca de su mascota, ellos son orgullosos, inhibidos, escrupulosos, desconfiados, reservados y antipáticos ( $p$. 7). Unas páginas después, Cecil añade: “En el fondo es un ingenuo; de ahí proviene su discutido encanto pueril, esa ilusión que hace que no envejezca como sería lógico y que tanto me conmueve", (p. 11). Este encanto pueril mencionado por Cecil es indisociable de la manía de su amo por la comparación: "Le encanta comparar". (p. 6). En efecto, tal un niño que descubre el mundo, Mujica Láinez se deleita en comparar lo desconocido con los recuerdos que habitan su cabeza:

\footnotetext{
El viaje de la estancia a la quinta es largo y, según he oído comentar, notable por la belleza de sus panoramas. El Escritor dice que le recuerda a Escocia, pero a él cualquier paisaje, cualquier sitio le recuerda otro, pues ha ambulado mucho, y si su memoria no le brinda de inmediato la perseguida imagen, me parece que la substituye con una aproximada, para no quedarse sin su comparación. P. 6.
}

Equivocadamente se ha encasillado a Mujica Láinez como un dandi anacrónico, un hombre del 80 amargado con sus coetáneos. Lejos de los mencionados tópicos, Manucho fue un hombre con principios de vida sabiamente definidos que no respondía a fenómenos de moda ni a antojos materialistas. Un ser singular, con una ética única.Véase esta cita extraída de la página diecisiete que cito en su totalidad por su fidelidad al pensamiento del escritor argentino:

Aparecen, de tanto en tanto, periodistas: cada vez menos, porque ya ha dejado de ser "noticia", por ventura, el retiro del Escritor a estas soledades. Al principio les intrigaba el porqué de ese alejamiento. No lo entendían entonces y tampoco lo entienden ahora pero el hecho ha dejado de interesar ya a esos núcleos inofensivos que se alimentan [...] de lo que les sucede a los que persiguen sus vidas fuera del montón.

No comprendían, en lo que a mi amo respecta, su necesidad de apartarse, a esta altura del camino, de las sendas demasiado transitadas, para que ese otro "smog" que es la novelera bruma no le impidiese ver con lucidez dentro de sí mismo. Como él se caracterizó, pues la frivolidad es uno de sus muchos ingredientes psicológicos, por la tenacidad con que participaba del mundano estrépito, aun en sus manifestaciones más tontas — sin captar que al narrador todo lo nutre-, resolvieron al fin que su exilio voluntario constituía una actitud, una "pose" más, y un medio astuto para continuar llamando la atención con un nuevo artificio, y cada vez que el Escritor regresó a Buenos Aires, muchos lo comentaron como si fuese una traición y un testimonio de su flaqueza. Varios de ellos se negaron a discernir que, al alejarse, el Escritor no había firmado un pacto con nadie; que no se había convertido, de la noche a la mañana, en un ermitaño o un Fausto al revés. A la imagen convencional del mundano, substituyeron, elementalmente, la imagen convencional del anacoreta imposible. No entró dentro de sus esquemas la idea de que pudiera pasar un mes y medio en la serrana soledad y largarse luego a estar una semana en la metrópoli; una semana en el curso de la cual, flamante provinciano, se apresuraría a recuperar lo inalcanzable de los teatros, de los cines, de los almuerzos, de los salones, de los cafés, de la amistad. Y no percibieron que mientras reanudaba, pasajeramente, su caricaturizado y explotado trajín anterior, la visión de la quinta remota enriquecía su seductor poderío y lo atraía más que nunca. Desconcertados o despechados, terminaron por dejarlo tranquilo; resolvieron que perdía su condición de "noticia"; que lo probable es que sus contradicciones respondieran a los mecanismos propios de un viejo' caprichoso, y apartaron de él los reflectores de la publicidad, que antaño lo habían hostigado. Eso refirmó su certidumbre de que no había errado al ausentarse. No le importó que alguno recurriese, en la charla, a la metáfora remanida de la torre de marfil. Para meterse en una 
torre de marfil — pensó- hay que conquistarla. Al contrario de lo que se dice, la torre de marfil es el gran premio y la gran aspiración de quienes son sinceros consigo mismos. (p. 17)

Todas estas actitudes cultivadas en su intensa vida mundana, fueron también consecuentes con esa necesidad de distinguirse de esa masa urbana de la que nada sabía y con la que nada tenía que ver, para reivindicar hasta sus últimas consecuencias el apego a sus raíces, al pasado glorioso de su estirpe representada en los próceres de la nación. Cuando un escritor rechaza la sociedad en la que no se reconoce, tiende a refugiarse en su propio yo para evitar que los cambios experimentados no provoquen una disolución de la identidad como lo ha señalado Quesada: "Ese anclaje en el pasado para él significaba mucho, pues era una forma de sentirse parte de una vasta comunidad cultural y de seguir recibiendo a través de estos próceres de la patria las esencias de lo argentino". (Quesada Portero, 2010: 149).

Otro rasgo determinante del carácter de Mujica Láinez presente en Cecil es la atracción por lo esotérico (p. 39). Su superstición, prolongación inevitable de su amor por los objetos, era conocido de $\operatorname{todos}^{11}$ pero aun así la vuelve a ratificar afirmando que sí es supersticioso "Como Byron. Doy por esa ruta el paso inicial hacia el misticismo. Curso, sin proponérmelo, el primer grado inferior de místico", (p. 16). Esta respuesta a una pregunta realizada durante una entrevista deja entrever por otra parte un Mujica Láinez bondadoso y burlón.

Hace falta completar estas creencias en la superstición, la reencarnación y lo cabalístico con lo que el autor dijo antes de morir: "espero que Dios me perdone todo lo que yo ya me he perdonado". Hasta el final de su vida, Mujica Láinez conservó esta agilidad mental, este humor negro que le permitieron a lo largo de su vida utilizar el arma de la frase asesina; esta expresión precisa que dejaba callado a todos por su tono burlesco y desafiante. No me resisto a mencionar un ejemplo más. Al momento de hacer referencia a la dependencia emocional que Heliogábalo sentía por su abuela termina diciendo: "Lo cierto es que él no se sentía seguro si no tenía a su abuela al lado — suponemos que en las orgías no... aunque ¡quién sabe! - " (p. 56). En Cecil no sólo asoma el humor, que, recordémoslo es una prueba de inteligencia y sabiduría, sino juicios personales sobre conductas reprochables de los monjes griegos que pudo visitar en su primer viaje a Europa ("Una cruz de madera del Monte Athos, del que visité cuatro monasterios y entreví los monjes archicélebres, copistas de iconos y perseguidores de niños suecos" (p.14) y el lugar de parada para objetos "perdidos" que representa el banco municipal de Buenos Aires:

\begin{abstract}
Me lo robaron; parece increíble, dado su peso, pero me lo robaron, y lo recuperé en el Banco Municipal de Buenos Aires. A esta otra pieza me la robaron también y la recobré junto con la anterior. El Banco Municipal es la desembocadura de muchos complicados arroyos. P. 15.
\end{abstract}

Esta faceta juguetona de su personalidad es indisociable de su pasión por captar la instantaneidad de un momento y narrarlo; en una palabra, relatar vivencias. Para Mujica Láinez, la escritura es un motivo de felicidad, un período de exaltación aliviador durante el cual su figura de narrador innato se liberaba: "Escribo, aun cuando trato un tema dramático, en medio de la alegría de la crea $\neg$ ción. Para otros, según he oído, esos son los grandes momentos que torturan. Para mí no, por suerte. Son, al contrario, los del alivio que exalta a quien da vida.", (p. 18). Ahora bien, al colocar el punto final de una obra, entra en un periodo de considerable angustia, invadido por el miedo inconfesable de no tener la capacidad para redactar otra historia: "La impresión de ausencia, de carencia, de orfandad — esa es la palabra: orfandad-, que reemplaza entonces a las sensaciones radiantes que me dio el libro en gestación, alcanza en esas oportunidades a extremos casi dolorosos", (p. 18).

Presentar el carácter de una persona en unas pocas líneas es siempre un ejercicio costoso y azaroso por la tarea de búsqueda y elección de los rasgos a destacar. Recordemos entonces a Mujica Láinez como un hombre sincero, optimista, comprometido con su oficio de 
escritor, bromista, irónico, inconsciente a veces, díscolo y apegado a sus seres queridos a los que se entregaba sin reserva y padecía, al momento de alejarse de ellos, una congoja insospechable que influía en su ánimo tal polilla en libro: "Ese repentino eclipse de dos seres tan estrechamente ligados a su intimidad, fue lo que operó sobre las fibras emotivas de mi amo." (p. 74).

Añadamos un dato que aparece de manera implícita en Cecil y que pocos conocen o, por lo menos, no quieren desvelar. Me refiero a la atracción de Mujica Láinez por lo erótico y a la relación homosexual que mantuvo con un tal Leonardo. La homosexualidad de Mujica Láinez es un hecho incontestable como lo explicó Abelardo Castillo en una entrevista: "era homosexual -cosa que por lo demás nunca ocultó, y hasta se jactaba de serlo ${ }^{12}$-". En Cecil, se asume explícitamente esta relación que empezó el día que el Escritor conoció a Leonardo en el hotel vecino de Miss Noli (p. 65) y

desde entonces vimos a Leonardo a menudo, en el curso de los dos meses siguientes. Aprovechó, duran-te el primero, sus vacaciones, para quedar en la quinta una temporada; el segundo, vino los weekends. Mi amo se habituó pronto a su compañía. Era evidente que le gustaba la rápida percepción del muchacho; que lo divertían sus observaciones y las imágenes originales que usaba al conversar. P. 67

La intimidad creciente entre el estudiante arquitecto y su dueño incomoda a Cecil hasta tal punto que declara:

Me sacaban de quicio aquella intimidad, aquel
entendimiento exclusivo, y pese a que mi patrón
siguió trabajando en el acopio de materiales
para su "Heliogábalo", los días en que Leonardo
estaba ausente, el don que me permite recorrer los
arcanos de su espíritu me dejó apreciar hasta qué
punto rivalizaban allí, para atraer su atención, el
emperador joven y el joven arquitecto. P. 68 .

La intromisión de Leonardo transformó al dueño de la quinta hasta tal punto que en sus caminatas diarias Mujica Láinez, tal un enamorado: "estaba en la luna; sonreía, silbaba, cantaba, como un tonto" (p. 68) pero en su ausencia las tribulaciones del Escritor atormentaban a Cecil hasta desear su regreso "para que como antes sonriera y fuera feliz" (p. 68). Si dudas quedaban acerca de la naturaleza de su relación, véase este elocuente fragmento:

A mi amo lo hechizó. De noche, luego de que se habían retirado los demás, quedaban los dos en el fumoir, frente al Buda de Manchuria, oyendo música, particularmente la serie de los "Brandeburgueses" de Bach, que Leonardo le trajo de regalo a la mujer del Escritor. A continuación se encerraban arriba y yo, pegado a la puerta, los oía reír y charlar hasta tarde. P. 67.

Junto con Bomarzo y Los Libres del Sur ${ }^{13}$, Cecil es la novela más autobiográfica de Manuel Mujica Láinez pero también la obra en la que se asume explícitamente el deseo homosexual y el erotismo. Prueba de ello, la sorpresa con la que termina el capítulo "Visita guiada":

y cuando el Escritor cree que se deshace de él, el
intruso se mete en el cuarto de baño, no por motivos
obvios sino para admirarse ante las cincuenta "figas"
brasileñas que cuelgan de la pared sus brazos toscos,
sus manos que reproducen, con el pulgar dentro
del índice, el ademán desvergonzado, ritualmente
obsceno, que conjura la mala suerte. P. 16 .

Conforme pasan páginas y capítulos, el autor adentra al lector en su intimidad para que éste descubra por sí mismo, lejos de los atavismos convencionales, quién es realmente Manuel Mujica Láinez.

\section{Las claves interpretativas de su obra}

La interpretación de la obra de Manuel Mujica Láinez sólo puede ser comprendida a partir de las experiencias estéticas y éticas que agitaron su vida y conformaron su personalidad. El proceso de exégesis de una novela es un mecanismo complejo que va más allá del entendimiento del solo texto. Éste debe comprenderse teniendo en cuenta las coordenadas histórico-sociales de la época así como el contexto personal de creación de la obra. De acuerdo con lo expresado, Mujica Láinez suele dar ciertas pistas de acceso a su obra en sus novelas.

Si bien es cierto, cada autor, consciente o inconscientemente, organiza su obra en torno a una serie de postulados filosóficos, estéticos 
e ideológicos. Conviene, con respecto al autor argentino, señalar algunos de los conceptos recurrentes que integran su obra. Yamencionamos anteriormente el sitio prominente que reserva a los objetos por lo que sólo reproducimos una cita aclaratoria al respecto:

Lo primero que percibí, en su penumbra interior, fue la jerarquía esencial que concede a los objetos. Quizás crea en ellos más que en las personas. Entiendo que ha subrayado esa relación en alguno de sus libros. Los objetos lo preocupan y, no obstante el largo tiempo transcurrido desde que empezó a interesarse por ellos, continúan hechizándolo. (Cecil, p. 10)

La idea circular que tiene de la historia está relacionada con la concepción cíclica del tiempo que él defendía. Manuel Mujica Láinez pensaba que el mismo tiempo se repetía en una sucesión de épocas históricas que tenían como única novedad a las personas, siendo iguales las situaciones y sucesos ocurridos. Astuto observador de la realidad, el cuentista porteño demostró la validez de sus creencias aludiendo a la circularidad del tiempo cósmico: el incansable repetir de las estaciones y la regularidad de los fenómenos celestes. Creía con firmeza en la posibilidad de un tiempo circular, tal como lo había enunciado Hesíodo en sus metálicas y cíclicas repeticiones, o la moderna filosofía de Hegel, Spengler o Vico ${ }^{14}$. Este planteamiento es evidente en Cecil ya que la novela comienza y termina con el mismo párrafo:

Creo que lo he fascinado, y sé que él me ha fascinado también. Presumo que nos perteneceremos el uno al otro hasta que la muerte ocurra. ¿Cuál vendrá primero, desnuda, fría y alta, a visitarnos? ¿La suya, la mía? La mía probablemente, pese a que él está lejos ya de ser un niño, porque mi vida, por inexorable capricho biológico, cuenta con un plazo mucho más corto que el acordado en general por el Destino a los de su privilegiada especie. (Págs. 1 y 81).

En una entrevista realizada por Luis Antonio de Villena (Cerrada Carretero, 1990: 1369), Mujica Láinez explicó: "El tiempo es una invención humana, creada para justificar la historia y para explicar el Progreso, ese gran absurdo". Con Mujica Láinez las palabras no se pronunciaban en vano y como consecuencia siempre reflejó en sus obras esta peculiar y desengañada postura. El ejemplo paradigmático es su novela De Milagros y de Melancolías (1969) en la que asistimos a "una disolución del tiempo histórico (no hay ni una sola fecha, porque lo narrado ha podido ocurrir antes, después o simultáneamente a nuestra temporalidad humana)." (Cerrada Carretero, 1990: 1329). Siendo así su concepción del tiempo y de la vida en general, cobra ahora todo su sentido el cariño y la atención que dedicó a los objetos, más duraderos que el amor humano propenso a las desilusiones y al engaño.

Por una serie de acontecimientos inesperados que le sucedieron ${ }^{15}$, Manuel Mujica Láinez creyó desde muy temprano en la omnipotencia del destino. Vinculados a la concepción cíclica del tiempo que acabamos de tratar, el destino y la fatalidad aparecen una y otra vez en Cecil. Como se ha señalado previamente, Mujica Láinez es un ser supersticioso que siente especial atracción por los fenómenos esotéricos. No extraña por tanto que el Destino aparezca reiteradas veces en sus novelas como una especie de demiurgo más emparentado con la filosofía gnóstica que con la platónica, es decir, el alma universal, principio activo del mundo. De no ser así, en Cecil, la palabra "destino" está escrita con minúscula, sino, siempre se recalca con la mayúscula: "Mi dueña me señaló, en la jauría, pero yo barrunto que junto a ella estaba, en ese segundo crucial, el Destino, y que fue él quien condujo su mano ${ }^{16 "}$ (p. 6).

En la misma línea, el escritor argentino siempre ha resaltado la ingenuidad de los hombres al desdeñar las señales del destino atribuyéndolas a simples coincidencias o hechos misteriosos. Al contrario de muchos, el porteño siempre ha creído en el poder de los mitos y de las leyendas para explicar y completar la Historia encontrándose éstos en los orígenes de una nación ${ }^{17}$ en tanto representantes de la identidad de las mismas:

¿Qué hacerle? ¿Destituir a la Leyenda de su función de auxiliar poética de la Historia? ¿Desterrarla de un texto en el que lo lírico ocupa amplio espacio? Sería necio e inútil. Ella triunfa siempre, con su seducción. Va aquí, pues, La Leyenda de los 
Primeros Señores de la Quinta. Se redondea con trocitos multicolores, como una colcha de anciana. Ni mi amo, que la apuntó, ni yo, que en su mente la recorrí, damos fe de su autenticidad. En el comienzo de cualquier cronología o genealogía que se respete, campean la Fábula y el Mito. También asoma en ella, por cierto, la Verdad. Al sesudo, al archivero, al antipoeta, corresponderá separarlos. Yo no me atrevo. (Cecil, p. 28)

A tal efecto, la residencia del escritor, El Paraíso, es un lugar encantado que corresponde idóneamente a la cosmovisión de Mujica Láinez dado que está poblada de un fantasma inglés, Mr. Littlemore, que el escritor argentino ha documentado: "el Escritor se consagró a reconstruir la elemental existencia de su huésped incógnito. Procedió como cuando preparaba sus novelas históricas, acopiando materiales de todas las fuentes". (p. 25). El fantasma y las visiones pueblan la quinta de mágica sugestión y gracias a Cecil y su cronicón, Mujica Láinez adquiere un halo legendario.

\section{Los proyectos literarios abortados}

El período de "vacío" entre el punto final de una novela y el principio de la redacción de otra aterrorizaba a Mujica Loáinez. Este intervalo de tiempo le provocaba desasosiego: "He cerrado el último capítulo de un libro; me he despedido de los personajes que durante meses, quizás durante años, poblaron mi imaginación y mis horas, y de repente me siento despojado, vacío" (Cecil, p. 28). Su preocupación por la página en blanco llegaba hasta tal punto que, a veces, la precipitación lo hacía incurrir en errores tal y como nos lo confiesa Cecil:

Había redondeado, una tras otra, dos novelas de aliento, y me sentía desposeído como nunca. A tal grado de intensidad llegó mi preocupación, que me equivoqué, y me lancé a planear otro libro de igual trascendencia: el que debía ser la novela de los príncipes misteriosos que, después de la victoria de Pizarro, se refugiaron en Machu-Picchu y tuvieron un trágico desenlace. Había leído ya incontables textos de comentaristas e historiadores, cuando, listo para iniciar la construcción, me amilanó el esfuerzo que me aguardaba. En horas se desmoronó el edificio en cierne y estuve a la vera del pánico.
Me refugié en otro tema, en la idea de "El entierro del conde de Orgaz", una novela que hubiera sido un conjunto de cuentos enlazados, cada uno de los cuales tendría por personaje e uno de los inmortalizados por el Greco, en su cuadro célebre, y que se reunirían en el capítulo postrero, dentro del taller del pintor, frente a la tela blanca. Leí y anoté, pero dejé caer al Greco, si bien en Toledo, más tarde, quizás por sugestión de la atmósfera, volví a tomar apuntes. En verdad, y pese a que la razón me repetía que no me intranquilizara, pensé en esa época fatal que ya no sería capaz de escribir. (Cecil, p. 29)

En otra ocasión, la reproducción de una conversación con uno de los pocos periodistas que vinieron al Paraíso, nos enteramos del nuevo proyecto literario de Mujica Láinez:

\footnotetext{
Al punto reconocí al muchacho del retrato que hay en la biblioteca, al de la mascarilla, también, de terracota, que para él modeló un joven artista cordobés, Y recordé que en el curso de las "visitas", cuando un inquisidor le preguntó por esas efigies, el patrón de la quinta contestó que se trataba de Heliogábalo. (Cecil, p. 20)
}

Es evidente la ilusión de la fe en sí mismo, la embriaguez incomparable que procura el placer de narrar, en este caso, las aventuras de Heliogábalo, un personaje cuyas características (muchacho débil, vicioso, loco, de despreciable trayectoria) lo sedujeron indiscutiblemente recordándole algunas vicisitudes personales. El escritor argentino dedicó seis largos meses a la documentación histórica de su nuevo proyecto acumulando notas en sus gruesos cuadernos azules; vacilando en la organización de los materiales recopilados, y, sobretodo, en la historia que pretendía contar. Mujica Láinez se singulariza por afrontar cada nuevo reto literario como si desconociera absolutamente todo del tema que tratará, tomando distancia con los lugares comunes y los prejuicios subjetivos inherentes al género humano. Tal un escolar, lee, relee, anota, subraya e investiga hasta agotar el más mínimo detalle dejando notas manuscritas en los márgenes de las obras consultadas. A pesar de todos estos esfuerzos nunca consiguió hilvanar su idea de novela sobre Heliogábalo con los materiales acopiados. Mujica resuelve en Cecil este fracaso evidente y consigue con 
ingeniosidad hacer de este proyecto abortado un capítulo de novela.

Otro de los grandes deseos frustrados de Mujica Láinez fue el no haber publicado ese libro de tema americano que planeaba escribir después de la publicación de El Unicornio (1965). Este libro, titulado El Inca, tenía como protagonista al Inca Garcilaso de la Vega. Desafortunadamente ese anhelo nunca vio la luz y en su lugar publicó De Milagros y de Melancolías (1969). Sabemos con la lectura de Cecil que Mujica Láinez nunca abandona un proyecto o por lo menos siempre consigue rizar el rizo. En la penúltima carta que mandó a su amigo Luis Antonio de Villena antes de morir (30/01/1984) leemos con placer la confesión de Mujica Láinez:

\begin{abstract}
Ahora me ocupo, algo lánguidamente, de reunir materiales con destino a una novela que se ubicará en tiempos de nuestro tirano Juan Manuel de Rosas (hacia 1830-1840). Pienso referir en ella la breve historia de un muchacho a quien he injertado en mi genealogía y a quien haré morir, por amor y por error, en la batalla de Chascomús, a la edad de 19 años. Lo curioso es que ese personaje será igual que yo fui en ese período de mi vida, e iguales sus parientes inmediatos a los que me rodearon entonces. (Villena, 1984: 10).
\end{abstract}

Esta novela inconclusa titulada Los Libres del Sur, contempla los primeros años de vida de nuestro autor y trata, como lo deseó inicialmente con El Inca, un tema americano.

\section{Ajuste de cuentas personales}

Cecil es una obra única por su carácter de autobiografía novelesca pero también por la entrega espontánea del autor. Empero, más allá de las inéditas confesiones de Mujica Láinez, uno no debe caer en la estulticia de un optimismo desenfrenado. Indudablemente, Mujica Láinez aspira con este libro a legitimar su labor de escritor. No olvidemos que Cecil, publicada en 1972, fue la primera obra ideada y redactada en el Paraíso. En tiempos oportunos, Mujica Láinez acometió contra su equivocada reputación de dandi estrafalario señalando que un vividor no puede ser escritor, crítico de arte, periodista, traductor y diplomático. En la página doce, cuando Manucho dirige la visita guiada a su casa, recurre al recurso de la filiación artística familiar para legitimarse en el panorama cultural argentino: ""La vitrina con libros familiares" (la tragedia del clásico, tío tatarabuelo, que imitaba a Alfieri ${ }^{18}$; las publicaciones del tatarabuelo periodista, el "mártir ${ }^{19 " ; ~ l o s ~ v o l u ́ m e n e s ~ y ~ f o l l e t o s ~}$ que más o menos justifican la tradición literaria de la estirpe; el halo romántico)" (p. 13). Más adelante añade: ""A los antepasados de mi mujer se los distingue por las espadas; a los míos, por las plumas"” (p. 13).

Mujica Láinez no sólo se contenta con asentar su posición de escritor gracias a la tradición literaria familiar sino que destaca en Cecil el rigor de las lecturas. Así, la exacta enumeración del catálogo de obras leídas (p. 45) durante medio año para preparar la escritura de Heliogábalo es un argumento de facto que destruye por sí solo la supuesta frivolidad del Escritor. En este sentido es pertinente traer a colación un fragmento del prólogo de Alejandra Larea a Los dominios de la belleza (2005), antología de relatos y crónicas de Mujica Láinez:

\footnotetext{
Del lado del elogio, la frivolidad se convierte en un goce profundo de la vida, en una capacidad para disfrutar de lo cotidiano y compartirlo en familia y con amigos. Del lado de la crítica, en cambio, la frivolidad se despliega en otro sentido: Mujica Láinez sería fútil, veleidoso, inconstante; su obra, por extensión, insustancial y ligera. Frente a la obsecuencia del círculo de pertenencia y la excesiva demanda de los medios que logran convertirlo en una suerte de "opinólogo" de su época, un cierto menosprecio acompaña el rechazo de lo que representa su figura de escritor tanto por su conservadurismo político como por el éxito de sus libros.
}

Pero Mujica Láinez no sólo fue un novelista. A propósito de su incansable labor de crítico de $\operatorname{arte}^{18}$ en La Nación (1949-1969), no podemos dejar de mencionar esta tajante frase pronunciada por Cecil: "No olvidemos que fue crítico de arte y que impulsó a una generación semirrelegada ${ }^{20} "$ (p. 12). El whippet participa de la legitimación personal y profesional de su amo narrando la crónica de sus aventuras y confesando en ocasiones lo que nunca pudo decir en voz alta. Citemos otro ejemplo: "A 
diferencia de otros novelistas — ¿habrá que recordar el ilustre ejemplo de Proust? - mi dueño tuvo la suerte de no necesitar salir de su casa, en busca de documentos" (p. 34). Casi al final de la novela, Cecil acude esta vez a una eminencia nacional, en la persona de Leopoldo Lugones: "Veía desfilar, por las galerías de su alma, a Lugones —a quien mi amo trató diariamente, años y años atrás, durante su época de periodista, y de quien conserva una carta generosa-," (p. 78).

Como vemos, Mujica Láinez juega con las voces discursivas, unas veces recurriendo a la función apelativa mediante el uso de la primera persona del plural (primer ejemplo), otras, utilizando la raya a modo de inciso. La alternancia de ambos mecanismos permite al escritor argentino cansar al lector sin perder de vista su objetivo principal: acabar con esta imagen de dandi anacrónico, estrafalario y bohemio.

\section{A modo de conclusión}

Cecil recupera retrospectivamente los sucesos más importantes de la vida de Manuel Mujica Láinez desde su instalación en el Paraíso de Cruz Chica en el año 1969. El whippet puede vislumbrar en lo más recóndito de la mente de su amo porque lo ama sinceramente, sin reclamar nada más que su afecto y atención. El amor, en todas sus manifestaciones y pasiones desplegadas, es el concepto clave del mundo literario de Mujica Láinez que éste reafirma esta vez en boca de su animal de compañía.

A diferencia del Flush de Virginia Woolf, Cecil no es una ficción sino una autobiografía novelesca que alberga confesiones inéditas de Manuel Mujica Láinez. Contar su vida desde una perspectiva autobiográfica real hubiera sido de una pretensión vanidosa limitando además los juicios críticos y terminando con el pacto de lectura propuesto al inicio de la novela que propugna una impecable fusión entre lo real y lo maravilloso. Con un lenguaje espontáneo, cercano e irónico captamos la poesía de sus recuerdos, sus pasiones, milagros y melancolías pero sobretodo la intensidad de sus luchas personales.

Cecil, hasta hoy injustamente olvidada por la crítica literaria, ocupa un lugar central en la creación artística del novelista argentino. En primer lugar, por mostrarnos el escritor bonaerense en la simplicidad de la cotidianeidad; segundo, porque se va delineando página tras página, el verdadero carácter de Manuel Mujica Láinez. No asoma nunca el personaje público, el alter-ego creado para afrontar el estruendo mediático y mundano de la capital; en tercer lugar, las asimilaciones equivocadas de periodistas y literatos que equipararon Manuel Mujica Láinez a un dandi lo obligaron a defenderse. En Cecil, el escritor argentino dio prueba del arduo trabajo matutino y vespertino así como de una estirpe dedicada al Arte desde los Varela, pasando por los Cané hasta culminar en los Láinez. Como él sabiamente señalaba, no es lo mismo ser frívolo que ser superficial ya que el frívolo puede ser inteligente, mientras que el superficial es irredimiblemente idiota. En último lugar, hojear a Cecil es darse el lujo de conocer a fondo el Escritor: sus aspiraciones, alegrías, miedos, desilusiones y fracasos. De esta manera, descubrimos los proyectos literarios que nunca llevó a cabo como Juana la Loca, Heliogábalo o El Inca. El autor nos revela sus zozobras; el vacío que lo conquista cuando da por terminado un libro hasta que, de nuevo, lo contagie la alegría de la chispa creativa.

La introspección permite conocerse, aceptarse mejor, pero sobre todo, darse a conocer a los demás. Manucho, desde su partida al Paraíso en 1969 hasta la publicación de Cecil en 1972, estuvo casi tres años sin escribir abrumado por el ajetreo de la mudanza a la que siguieron las reformas de la mansión y su consecuente acomodación que había que conciliar con la visita de familiares y amigos. Seguramente necesitaba saldar esta parte de su vida, repensarla, analizarla y digerirla para poder, nuevamente, escribir. Para Mujica Láinez, Cecil fue su catarsis literaria. Como ningún otro libro, detalla entre líneas las claves interpretativas de la obra de Manuel Mujica Láinez: su pasión por los objetos, la circularidad 
del tiempo, el Amor como motor de la vida en su abanico de pasiones humanas, el Destino y la trascendencia de los mitos y leyendas para explicar el origen de la Historia oficial.

Esta novela no falla a los temas recurrentes que rodean a la obra de Manuel Mujica Láinez, esto es, la belleza en todas sus manifestaciones y concepciones, la afición por la historia, la nostalgia, la melancolía, la creencia en lo esotérico, la pasión por los objetos, la presencia del amor que todo lo puede y el lento, pero desgarrador, fluir del tiempo que en un momento dado borra las fronteras entre la verdad y la leyenda. Finalmente, nos compete a nosotros lectores, sacar nuestras conclusiones al confrontarnos con la imagen literaria que el escritor quiso ofrecer en sus memorias.

\section{Notas}

1. Al respecto se puede consultar el artículo de (Niemetz, 2010).

2. Se recomienda la lectura del artículo de Craig (1984) y del libro de Diana García Simón (1998).

3. Véase al respecto María M. Caballero Wangüemert (2000).

4. Cecil (1972) es un libro cuyo título viene del nombre del perro del escritor. Así lo nombró el escritor argentino ya que le fue obsequiado el mismo día en que conoció al fotógrafo Cecil Beatón en la estancia San Miguel de los Cárcano, en Ascochinga. Cecil, p. 11.

5. Apodo heredado de su padre Manuel Mujica Farias. Manuel Mujica Lainez era por tanto Manuchito y eso hasta terminar la adolescencia. Fue luego cuando amigos íntimos y familiares empezaron a llamarlo Manucho. Véase al respecto (Roffé, 2001: 107).

6. Edición de Diana Secker Tesdell, New York, Alfred A. Knopf, 2010. Completan esta edición "Ava's apartment" de Jonathan Lethem; "Garm, a hostage" de Rudyard Kipling; "The emissary" de Ray Bradbury; "There I was, stuck with Bubsy" de Patricia Highsmith; "Josephine has her day" de James Thurber; "Seeing eye" de Brad Watson; "Her dog" de Tobias Wolff; "Sir Henry" de Lydia Millet; "Barking man" de Madison Smartt Bell; "A yellow dog" de Bret Harte; "The story of two dogs" de Doris Lessing; "The hermit's story" de Rick Bass; "Flight" de Thomas McGuane; "My lord you" de James Salter y "Black dog" de Penelope Lively.

7. Con un prólogo de Gerald Durrell, Siruela, 2005.

8. Yo Siherden Emblem O'Neal, a quien mi familia y amigos me llaman Blemie, a consecuencia de mi edad y de las enfermedades que me agobian, transmito a la mente de mi amo lo que deberá ser mi última voluntad y testamento. En http://www.amedea. org.mx/cuentos.html, consultado el 20/03/2014.

9. Charles Baudelaire. 1964. "L'homme et la mer" en Les Fleurs du mal. París: Flammarion.

10. Después de haber dedicado dos largos años a la instalación y organización de su nueva morada en Cruz Chica.

11. Manuel Mujica Láinez dijo en una conversación con amigos: "Estoy absolutamente seguro que voy a vivir otra vida, cosa que representa, sin lugar a dudas, un alivio ante la pavorosa idea de la muerte. Soy muy supersticioso y cabalístico, lo que de manera alguna quiere decir que renuncie a cualquiera de mis otras creencias. Me considero católico, pero en lo hondo de mi subjetividad, ello no me parece irreconciliable con una cosmovisión esotérica".

12. Entrevista de Alejandro Margulis a Abelardo Castillo publicada en http://www.ayeshalibros. com.ar/anteriores/reportajes/reportajescastillo. htm, 2001.

13. Al fallecer, dejó tres capítulos terminados de Los libres del sur, una novela sobre la rebelión de los hacendados bonaerenses contra Juan Manuel de Rosas en 1838. Esa novela era un retorno a la memoria familiar, a los orígenes que lo emparentaban con Miguel Cané. Se pueden leer los capítulos inconclusos en Sur. Homenaje a Manuel Mujica Láinez (1910- 1984), (1986).

14. Véase Hegel, Fenomenología del espíritu, traducción de W. Roces, México, FCE, 1982; Oswald Spengler, La decadencia de occidente (Der Untergang des Abendlandes. Umrisse einer Morphologie der Weltgeschichte en alemán), proemio de José Ortega y Gasset, traducción de Manuel G. Morente, Barcelona, RBA, [1er volumen Viena, 1918; 2. 
volumen Múnich, 1922], 2005; y Giambattsita Vico, La ciencia nueva (Scienza nuova), prólogo y traducción de José Carner, México, El Colegio de México, 1941 (1725).

15. Cabe recordar el accidente que mencionamos en el capítulo I de este trabajo que le dejó inmovilizado en la cama. Su abuela y sus tías le narraban cuentos familiares y populares para distraerlo; y la inesperada ruina del padre que les condujo a Francia donde nació la vocación de nuestro autor por la escritura.

16. Se repiten las referencias al Destino en las páginas 42,51 у 78 .

17. Se recomienda al respecto (Choin, 2012).

18. Juan Cruz Varela, tío tatarabuelo materno.

19. Florencio Varela.

20. Hace referencia a la llamada "Nueva generación argentina" de pintores abstractos.

\section{Bibliografía}

Caballero-Wangüemert, María. (2000). Novela histórica y posmodernidad en Manuel Mujica Láinez. Sevilla: Universidad de Sevilla.

Cerrada-Carretero, Antonio. (1990). La narrativa de Manuel Mujica Láinez. Tesis de Doctorado. Universidad Complutense de Madrid.

Choin, David. (2012). "Mito, memoria, tradición e identidad en Misteriosa Buenos Aires de Manuel Mujica Láinez". En: Metamorfosis en los espejos: identidad latinoamericana entre pasados y presentes, Anabel Gutiérrez (ed.) Mitologías hoy. N 5: 38-51.

Craig, Herbert. (1984). "Proust y Mujica Láinez: la memoria asociativa". En Cuadernos hispanoamericanos. $N^{\circ}$ 409: 101-105.
Cruz, Jorge. 20/02/2010. "Manuel Mujica Láinez". En La Nación.

Fernández-Lisso, Rubén. Marzo-Abril (2003). "Manuel Mujica Láinez El Hombre del sombrero gris". En: La Tecla eñe Revista digital, Año II - $\mathrm{N}^{\mathrm{o}}$ 7. Consultado el 11 de noviembre de 201 .

García-Simón, Diana. (1998). Paraíso, metamorfosis y memoria. La influencia de Proust y Kafka en la obra de Mujica Láinez. Berlín, Bern, New York, Paris, Wien: Editorial: Frankfurt/M.

Iriarte-Aristu, Julia. (1982). "Manuel Mujica Láinez y los objetos". En: Boletín Millares Carlo, No. 6: 327-336.

Larea, Alejandra. (2002). Los dominios de la belleza. Antología de relatos y crónicas. Buenos Aires: Fondo de Cultura Económica de España.

Mujica-Lainez, Manuel. 10/11/1953. Discurso en un banquete. La Nación.

Mujica Lainez, Manuel. (1972). Cecil. Buenos Aires: Sudamericana.

Niemetz, Diego. (2010). “La estética del Realismo Mágico en la obra temprana de Manuel Mujica Láinez". En: Anales de Literatura Hispanoamericana. Vol. 39: 391-407.

O’Neil, Eugene. (1940). La última voluntad y el testamento de un perro extremadamente distinguido. En http: www.cdgutierrezg. t umblr.com/post/23943544407/ el-testamento-de-un-perro, consultado el 20/03/2014.

Piña, Cristina. (2009). "Manuel Mujica Láinez: Del realismo a la parodia y la imaginación". Conferencia presentada en el Museo de arte Hispanoamericano Isaac Fernández Blanco de Buenos Aires. 
Quesada-Portero, Raúl. (2010). Bomarzo y el autobiografismo en la narrativa de Manuel Mujica Láinez. Tesis de Doctorado. Universidad de Granada.

Roffé, Reina. (2001). "Entrevista a Manuel Mujica Láinez". En: Cuadernos Hispanoamericanos, $\mathrm{N}^{\circ}$ 612: 107-116.

Secker-Tesdell, Diana (ed.). 2010. Dog's stories. New York: Alfred A. Knopf.

Soler, José Joaquín. (1976). A fondo. Emitido en Radio Televisión Española.
Sur. Homenaje a Manuel Mujica Láinez (19101984). 1986. $\mathrm{N}^{\circ} 358-359$.

de Villena, Luis Antonio. (1976). Antología general e introducción a la obra de Manuel Mujica Láinez, Madrid: Felmar.

de Villena, Luis Antonio. (1984). "En la muerte de Manuel Mujica Láinez: recordando a "Manucho". En Ínsula, N 450: 10.

Woolf, Virginia. (1998). Flush, Oxford: Oxford University Press.

\section{@) $\odot \Theta \Theta$}

Este obra está bajo una licencia de Creative Commons Reconocimiento-NoComercial-SinObraDerivada 4.0 Internacional. 